\title{
Introduction to Special Section on the System of Care Implementation Survey (SOCIS)
}

\author{
Robert M. Friedman, PhD \\ Krista Kutash, PhD
}

Measuring complex systems is a major challenge confronting children's mental health and other human service systems. Within the past 25 years, there has been increasing recognition that effective services for children and youth with serious emotional disturbances and their families requires, for example, a range of services; collaboration between a variety of service sectors, multiple organizations, parents and professionals; attention to careful planning; adaptation to change; performance measurement; and continuous quality improvement. While it has taken time for the field to distinguish these and other nuanced and multifaceted features of an effective system of care, the greater challenge may be to measure how well communities are doing in implementing such systems. The field is much more adept at measuring characteristics of individuals, or of discrete programs, than measuring complex systems with multiple components that connect and interact with each other in myriad and changing ways. The difficulty in measuring complex systems has held back progress in the field. The absence of an approach that can be used to assess how well individual communities and states are doing in implementing systems of care, in what areas they are doing well and not so well, and what the status of systems of care nationally has slowed progress in successfully developing such systems.

The articles in this Special Section of the Journal of Behavioral Health Services \& Research examine the national level of implementation of the core concepts contained within the Systems of Care (SOC) approach using a sample of 225 randomly selected counties stratified by population size and poverty level. Implementation was measured using the Systems of Care Implementation Survey (SOCIS), which was completed by 910 informants representing the major child serving systems (i.e., mental health, school, and other child agencies, such as child welfare and Juvenile Justice) and child mental health advocacy groups.

In the article by Boothroyd, Greenbaum, and Wang et al., ${ }^{1}$ the research design, instrument development, and pilot testing of the data collection strategy for assessing the level of SOC implementation is described. The results illustrate a strategy that would permit the collection of data on the level of implementation of children's systems of care principles from the perspectives of multiple stakeholders in a nationally representative sample of counties.

The article by Greenbaum, Wang, and Boothroyd et al. ${ }^{2}$ provides a detailed summary of the psychometric properties of the SOCIS, including documenting the factor structure, item performance, reliability, validity, and their association with different informant groups.

Address correspondence to Robert M. Friedman, PhD, Department of Child and Family Studies, Louis de la Parte Florida Mental Health Institute, University of South Florida, MHC 2335, Tampa, FL, USA. Email: kutash@fmhi.usf.edu.

Krista Kutash, PhD, Department of Child and Family Studies, Louis de la Parte Florida Mental Health Institute, University of South Florida, Tampa, FL, USA.

Journal of Behavioral Health Services \& Research, 2011. (C) 2011 National Council for Community Behavioral Healthcare. 
The article by Lunn, Heflinger, and Wang et al. $^{3}$ examines the differences between communities in their SOC implementation scores as measured by the SOCIS, showing that community-level characteristics are relevant in explaining this variance.

In the article by Kutash, Greenbaum, and Wang et al. ${ }^{4}$, a summary of the substantive findings regarding the national level of implementation of children's systems of care principles is provided. Overall, there were six factors rated above a 3, or the mid-point of a five-point scale: (1) values and principles, (2) individualized, comprehensive, and culturally competent treatment, (3) transformational leadership, (4) theory of change, (5) family voice and choice, and (6) management and governance. Nationally, approximately a quarter $(26 \%)$ of the counties surveyed rated themselves as having adequate levels of implementation on 11 or more of the 14 factors, while $75 \%$ rated themselves as having adequate levels of implementation on six or more of the 14 factors measured.

This Special Section describes a framework for system measurement, presents a measurement tool and approach, and offers results from the first ever effort to assess the status of systems of care in a random sample of communities around the country. It demonstrates that, as difficult as it is, it is feasible to gather such important data. It provides a benchmark from which future national progress in providing systems of care can be assessed and identifies particular aspects of systems of care in need of further attention. In other words, when it comes to complex systems as well as individual programs and children, you need to know where you are and where you are headed in order to successfully reach your destination.

\section{References}

1. Boothroyd RA, Greenbaum PE, Wang W, et al. Development of a measure to assess the implementation of children's systems of care: The Systems of Care Implementation Survey (SOCIS). Journal of Behavioral Health Services \& Research 2011; 38(3). doi:10.1007/s11414011-9239-x.

2. Greenbaum PE, Wang W, Boothroyd RA, et al. Multilevel confirmatory factor analysis of the Systems of Care Implementation Survey (SOCIS). Journal of Behavioral Health Services \& Research 2011; 38(3). doi:10.1007/s11414-011-9240-4.

3. Lunn LM, Heflinger CA, Wang W, et al. Community characteristics and implementation factors associated with effective systems of care. Journal of Behavioral Health Services \& Research 2011; 38(3).

4. Kutash K, Greenbaum PE, Wang W, et al. Levels of system of care implementation: A national benchmarking study. Journal of Behavioral Health Services \& Research 2011; 38(3). doi:10.1007/s11414-011-9242-2. 